GDL: M

$0-7$
U S DEPARTWTH OF COMUTRCE

IATIOHEI BULTIAC OTS STANDARDS

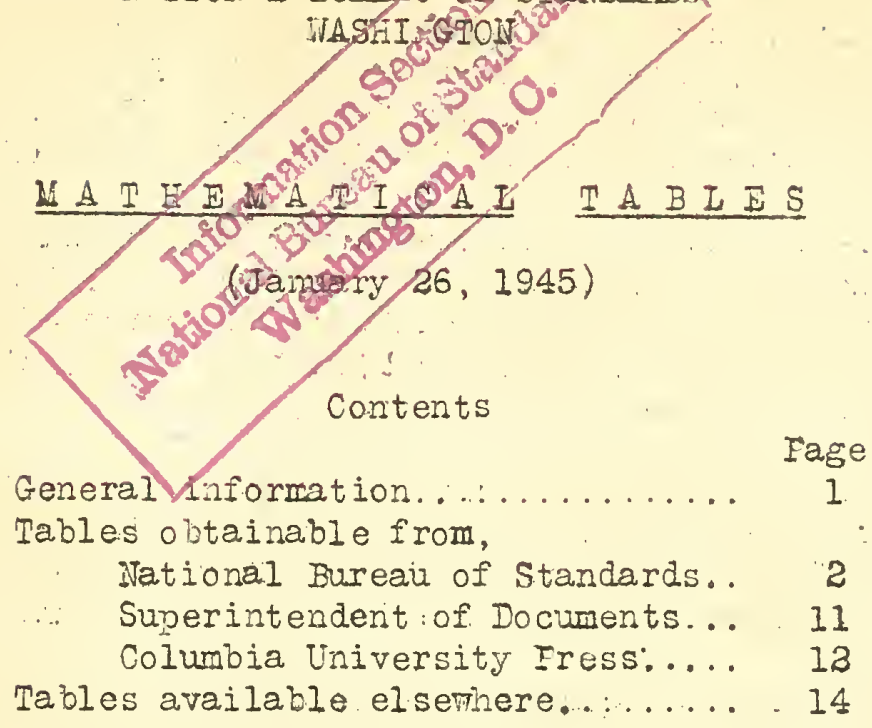

Letter

Circular

ILC-777

\title{
Generál Information
}

The Wathematical Tables Project, which prepared the mathenatical tables described herein ( in January 1933, and until liarch 1943, mas operated by the Federal Works Azency, Work Projects Adninistration for the City of Ner York under the sponsorship of the National Bureau" of . Standards."

When the Bork.Projects Administration discontinued this project, the sponsoring agency tcok over its operation with the support of the Office of Scientific Research and Development, the determination of the program being vested in the Applied liatheratics Fanel of the ivational Defense Research Committee. Under these new auspices, the najor emphasis.is being placed on the computation:of tables directly related to the war effort; but it is also planied to devote any available time to the important task of finishing various tables phich rere under way when the Worl Projects Administration was discontinued. Thus it has been possible to bring to Iinal completion. several volumes"; nor in the process of publication. A moiling list is maintained by the Bureau for those deciring to receive announcements of new tables as they become available.

It has been the policy of the Project to select for tabulation mathematical functions of fundamental importance in pure and applied mathematics. In the selection of" the functions to be tabulated and in the choice of the most useful range and interval of the argurnent, the Project has had the advantagc of a continual exchange of views with outstanding mathematicians, physicists and engineers, both here and abroad. 
The tables listed under this heading can be purchased from the Bureau at the prices indicated, unless otherwise stated. Fayment is required in advance and remittance should accompany the order. Then remitting, please make check or money order payable to the National Bureau of Standards.

The prices are for delivery in the United States and its possessions and in countries extending the frankirg privilege, that is, Canada and most of the Latin American countries. To other countries the price of UT2 to UTI6, inclusiv

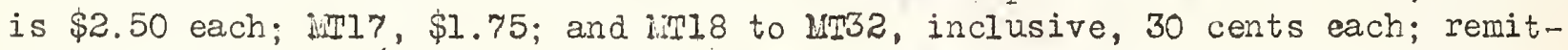
tance to be payablé in United States currency.

Copies of these publications (with the exception of MTII, LII5, IITIB and subsequent numbers, the editions of which are very limited) have been sent to various Government. Depositories in the United States, such as public libraries in large cities, colleges, and universities, there they may be consulted.

Wote. - The figures in square brackets denote the range and interval of the arguinent, and the nuraber of decimal places or significant figures in the tabulated entries. The letters "D" and "S" stand for "decinal places" and "significant figures", respectively... In ims, for instance, Si(x) is tabulated over the range from 0 to 9.999 , at intervals of 0.001 to 10 decimal places, and $\mathbb{E} i(x)$ is tabulated orer the same raige, for the same interval of the argument, to 10 significant figures."

NiT1. Table of the Pirst Ten Potiers of the Integers from 1 to 1000*.

(1939) viii + 80 pages; heavy paper cover, $8 \frac{2}{2}$ by $13 \frac{3}{4}$ in. Out of prin'

19T2. Tables of the Exponential Function $\mathrm{e}^{\mathrm{x}}$.

$$
\begin{gathered}
{[-2.5(.0001) 1 ; 18 D] ;[1(.0001) 2.5(.001) 5 ; 15 D] ;[5(.01) 10 ; 1207 ;} \\
{[-0.0001(.000001) 0.0001 ; 18 D 7 ; \Gamma-100(1) 100 ; 1957 .} \\
{\left[-9 \times 10^{-n} \cdot\left(10^{-n}\right) 9 \times 10^{-n} ; \text { for } n=10,9,8,7 ; 18 D\right] .} \\
\quad(1939) \times v+535 \text { pages; bound in buckram. Price } \$ 2.00 .
\end{gathered}
$$

Wir3. Tajles of Circular and Hyperbolic Sines and Cosines for Radian Arguments.

$$
[0(0.0001) 1.9999 ; 9 D] ;[0(0.1) 10 ; 9 D 7 \text {. Conversion table, }
$$

radians $\rightleftharpoons$ degrees. (1939) xvii +405 pages bound in buckram. Price $\$ 2$.

* Superseded by the more extensive table, "B. A. Wathematical Tables, volume IX, Table of Powers Giving Integral Powers of Integers," (1940) British Association for the Advancement of Science. 
194. Tables of Sines and Cosines for Radian Arguneints.

$\left[0(0.001) 25 ; 8 D^{1} ; \Gamma O(1) 100 ; 80\right]$. $\Gamma 1 \times 10^{-n}\left(10^{-n}\right) 9 \times 10^{-n}$; for $n=5,4,3,2,1 ; 15 D 7 ; \Gamma 0(0.00001) 0.01 ; 12 D 7$. Conversion table, radians $\underset{\gtrless}{ }$ degrees. Values of $p(1-p)$.

(1940) $x i x+275$ pages; bound in buckram. Price $\$ 2.00$.

UT5. Tables of Sine, Cosine, and Exponential Integrals, Volurne I.

$[0(0.0001) 1.9399 ; 917 ;[0(0.1)] 0 ; 9] 7$. Auziliary tables of $p\left(1-p^{2}\right) / 6$ and $p(1-p)$.

(1940) xxvi + 444 pages; bound in buckran. Frice $\$ 2.00$.

MT6. TajIes of Sine, Cosine, and Exponential Integrals, Volune II.

$$
\begin{aligned}
& \mathrm{Si}(x), C i(x):\left[0(0.001) 9.999 ; 10 D^{7} ; \Gamma 10(0.1) 20(0.2) 40 ; 10 D 7\right. \text {. }
\end{aligned}
$$

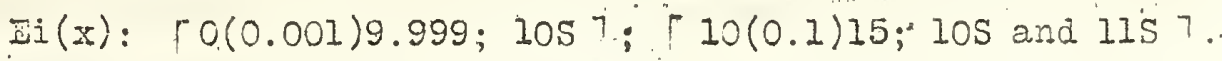

$$
\begin{aligned}
& -\mathrm{E} i(-\mathrm{x}):\left[0(0.001) 9.999 ; 957 ; \Gamma 10(0.1) 15 ; 140{ }^{\top} 7\right. \text {. } \\
& \text { Si }(n \pi \pm n) \text {, for } n=1,2,3 \text {; Ci(n } r / 2= \pm h) \text {, for } n=1,3,5 \text {; } \\
& \text { for } h=r 0(0.0001) 0.01(0.001) 0.05 ; 15 D ? \text {. } \\
& \text { Auxiliary tables of } p\left(1-p^{2}\right) / 6 \text { and } p(1-p) \text {. iultiples of } \pi / 2
\end{aligned}
$$
and other constants.

(1940). xxxvi1 + 225 pages; bound in bucleran. Price $\$ 2.00$.

iI?. Table of ilatural Logarithns, Volume I.

Iogarithras of the integers from 1 to 50,000 to 16 decimal places.

(1941) zviii + 501 pages; bousd in buckrass. Erice $\$ 2.00$ : 
iif?. Tables of Probability Functions, Volume I.

$$
\begin{aligned}
& H^{\prime}(x)=\frac{2}{\sqrt{\pi}} e^{-x^{2}} \text { and } H(x)=\frac{2}{\sqrt{\pi}} \int_{0}^{x} e^{-\alpha^{2}} d x \\
& \Gamma 0(0.0001) 1(0.001) 5.6 \text { (various) } 5.946 ; 15 D T . H^{\prime}(\pi) \text { and } I-H(x) \text {, }
\end{aligned}
$$
$[4(0.01) 10 ; 857$.

NI9. Table of Natural Logarithms, Volume II.

Logarithrs of the integers from 50,000 to 100,000 to 16 deciral places. $(1941) \cdot z v i i 1+501$ pages; bound in bcukram. Price $\$ 2.00$.

ililo. Table of idatural Iogarithms, Volume III.

Iogarithms of the decimal numbers from 0.0001 to 5.0000 to 16 decimal places. (1941) zviii + 501 pages; bound in buckram. Price $\$ 2.00$.

jirl1. Tables of the lioments of Inertia and Section induli of ordinary Angles, Chaninels, and Bulb Angles trith Certain Plate Combinations.

(1941) ziii +197 pages; bound in green cloth. Price $\$ 2.00$.

1W12. Table of Natural Iogarithms, Volume IV.

Zogarithms of the decimal numbers from 5.0000 to 10.0000 to 16 decimal places.

$$
\begin{aligned}
& \left.\operatorname{Iog}_{e} \pi ; \quad \Gamma 2(1) 10 ; 40 D\right] \\
& \log _{e}(1+x),-\operatorname{Jog}_{e}(1-x)\left[x=10^{-n}\left(10^{-n}\right) 10^{-n+i} ; n=1,2, \ldots 13 ;\right. \\
& (1941) \text { xzii }+506 \text { pages; bound in buckram. Price } \$ 2.00 .
\end{aligned}
$$

NI13. Tablo of Sine and Cosine Integrals for Arguments from 10 to 100.

$$
\begin{aligned}
& 10(0.01) 100 ; 10 D 7 \text {. iultiples of } \pi / 2 \quad[1(1) 100 ; 15 D 7 . \\
& \text { values of } p(1-p) \text { and } p\left(1-p^{2}\right) / 6 \text {. }
\end{aligned}
$$

(1942) . mai + 185 pages; bound in buckran. Price $\$ 2.00$.

III 4. Tables of Frobability Functions, Volune II.

$$
\frac{1}{\sqrt{2 \pi}} e^{-x^{2} / 2} \text { and } \frac{1}{\sqrt{2 \pi}} \int_{-x}^{x} e^{-\alpha / 2} d \alpha
$$




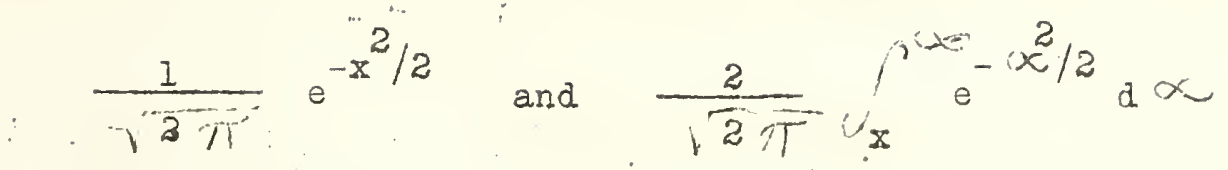

$[6(0.01)] 0 ; 75]$.

(1942). xis + 344 pages; bound in buckram. Price $\$ 2.00$.

IT15. The Hypergeonetric and Legendre Functions with Applications to Integra.1 . Equations of Potential Theory..... Chester Snor, National Eureau of Standards.

Comiled for workers in applied mathematics, its scone is intermedis betreen tables of numerical values of these functions and a treatise on their pure theory. The linear and quadratic transformations and analytic continvations of the ordinary hypergeometric function are derived and pritten out at length rith special. space devoted to the general associate Legendre functions, and to a smaller extent Heun's geveralization of the hypergeometric function. Applications to potential theory (9I pages) where the potential is given on surfaces of revolution "include rost of th elementary separable coordinate systems. Use is made of the potential equation in a form invariant to inversions, and from the point of viev of integral equations with Legendre's function, $Q_{m-\frac{3}{2}}$, of the second lrind as nucleus. Sone generalizations of Fourier's inte gral are obtained in whic the cistopinent function satisfies a second order differential equation o

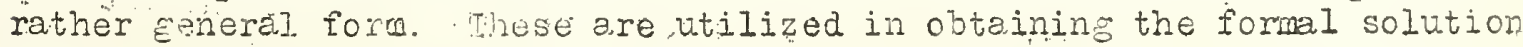
of various potential probiems. A set of normal functions is constmeted satisfying the Iame-Wantrin equation in "arnular" coordinates which include toroida? coordinates and oblate sphercidal as liniting cases.

Reproducedl by photo-offset process from original hahdmritten manu.script. (1942) 319 pages; bound in heavy taper covers. Price $\$ 2.00$.

LiTi6. Table of Arc Tan $\underline{x}$.

The principal value of the inverse tangent may be defined by the integral

$$
\operatorname{Arctan} x=\int_{0}^{x} \frac{d u}{i+u^{2}}
$$

The intervals between successive arguments have been so chosen, that interpolation to 12 decimals may be made with the aid of the second cent: differences which are.tabulated alongside of the entries.

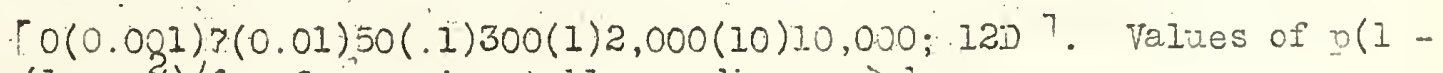
and $p\left(1-p^{2}\right) / 6$. Conversion table, radians $\Rightarrow$ degrees.

(1942) zIv + 169. pages; bound in buckram. Price $\$ 2.00$

II7. Liscellaneous Physical Tables: Planck's Radiation. Functions, and Electronic Eunctions.

I. Planck's radiation functions

(Reprinted from J. Opt. Soc. Arn, February 1940)

The functions evaluated by Tables I to IV are 


$$
\begin{aligned}
R_{\lambda} & =c_{1} \lambda^{-5}\left(e^{c_{2} / \lambda I}-1\right)^{-1} ; R_{0-\lambda}=\int_{0}^{\lambda} R_{\lambda} d \lambda \\
N_{\lambda}=2 \pi c \lambda^{-4}\left(0^{c_{2} / \lambda T}-1\right)^{-1} ; N_{0-\lambda} & =\int_{0}^{\lambda}{ }^{i r} \lambda d \lambda
\end{aligned}
$$

R $\lambda d \lambda$ is the energy emitted by a black body at absolute terperature, $T$, on the Kelvin scale, per unit time, per unit area, in a wave-length interva from $\lambda$ to $\lambda+\alpha \lambda$, throughout the solid angle $2 \pi$ steradians:

IT $d \lambda$ represents the number of photons enitted in the mave-len th range from $\lambda$ tn $\lambda+d \lambda$, per unit time, per unit area, throughout the solid angle $2 \pi$ steradians.

The tables evaluate these four functions of $\lambda T$ not only relative to their naxirum values; but also: for $T=1000{ }^{\circ} \mathrm{K}$ in absolute units (ergs or photons per $\mathrm{cm}^{2}$ per second. The values are given to five significant figures, first and second differences being provided to assist in finding $\mathrm{R} \lambda$ and $\lambda$ by interpolation; and there is provided a convenient method of correcting for small changes in the value of $c_{2}$ from that $\left(c_{2}=.1 .436 \mathrm{~cm} \mathrm{~K}^{c}\right.$ used in computing the tables. The function $i v$, is also evaluated for $T=1500,2000,2500,3000,3500$, and $6000{ }^{\circ} \mathrm{K}$.

\section{Ilectronic functions}

This table of 28 pages gives in five colurins the values for the velocity of an electron relative to the velocity of light, 3 ; $G=I /\left(1-\rho^{2}\right) \frac{1}{2} ; \beta G$; the energy in electron kilovolts, and the curvature of the electron path in a magmetic field tires the field $\mathrm{H} \rho$. The total energy", effective mass, and momentum depend on the functions" "Gand $3 G$. The energies in electron volts cover the range from 6 to $10^{10}$ electron volts so that the tables are applicable in the fill range of energies involved in nuclear and cosmic ray physics. In the range from 10,000 to $1.5 \times 10^{7}$ electron volts successive values differ by less than 1 percent in energy and curvature so that in nearly all pract'ical problems the tables rould be used thout interpolation. As relativistic equations most bo used throughout this range the tables will sare a great deal of laborious computation.

(1941) vi + 58 pages; bound in buclrram. Price $\$ 1.50$.

III 8. Table of the Zeros of the Legendre Polynomials of order 1-16 and the Weight Coefficients for Gauss iechanical Quadrature Forinula. 'A. N Ioman, IT. Davids, and A. Ievenson. Gauss' method of mechanical quadrature has the advantage over most methods of numerical integration in that it requilises about half the nuraber of ordinate computations. This is desirable when such computations are very laborious, or when the observations necessary to determine the 'average value of a' continuously varying physical quantity are very costly. Gauss' classical result states that, for the range $(-1 ;+1)$, the "best" accuracy with $n$ ordinates is obtained by choosing the corresponding abscissae at the zeros $x_{1}, \ldots . . x_{n}$ of the Legendre polynomials $P_{n}(x)$. With each $x_{i}$ is associated a constant $a_{i}$ such that 


$$
\int_{-1}^{1} f(x) d x \curvearrowright a_{1} f\left(x_{1}\right)+a_{2} f\left(x_{2}\right)+\ldots+a_{n} f\left(x_{n}\right) .
$$

The accompanying table computed by the iathematical Tables Project gives the roots $x_{i}$ for each $P_{n}(x)$ up to $n=16$, and the corresponding weight coefficients $a_{i}$, to 15 decimal places.

Reprinted from Bulletin of the American liathematical Society, October 1942. 5 pages, vith cover, 25 cents.

NI19: On the Punction $F(m, a, x)=\exp (-i x)$ F $(i n+1-i a, 2 x+2 ; i x)$. With table of the confluent hypergeometric function and its first

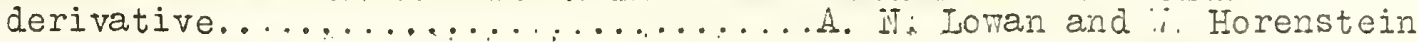

Confluent hypergeometric functions occur in numerous physical problems. They appear in the solutions of Iaplace's equation and the equations of rave rnotion and of diffusion when the physical problem involves kifie edges, parabolic cylinders; paraboloids of revolution, general ellipsoids, etc: Of particular importance to the quantum physicist is their occurrence as the solutions of the radial part of Schrodinger's equation for a Coulomb field and continuous values of the energy. Thus they are needed for the calculation of the scattering of charged particles from atomic nuclei, or of their binding by nuclei. In a more general form they also occur in the problem of dissociation of nolecules into atonic ions (and, of course, in the converse case of the formation of molecules).

This paper contains a table of $\mathrm{E}(\mathrm{n}, \mathrm{a}, \mathrm{x})$ and its first derivative for values of $x$ from 1 to 10 by steos of 1 , for values of a frun 1 to 10 by steps of 1 , and for values of the integer $m$ from 0 to 3 ; values in all cases are given to:? significant figures:

Feprinted from Journal of hathematics and Physics, Decenter 1942. 20 pases, with cover, 25 cents.

is20. Table of Integrals $\int_{0}^{x} J_{0}(t) d t$ and $\int_{0}^{x_{0}} y_{0}(t) d t \ldots \ldots$... I. I. Iowan and

Values of the tro integrals are given for $x=0(.01) 10$ to 10 decimal places. Reprinted from Journal of liathenatics and Physics, lay 1943. 12 pages, with cover, 25 cents.

HI21. Table of $J_{0}(x)=\int_{z}^{\infty} \frac{J_{0}(t)}{t}$ dt and related functions... A. i.. Lovan,

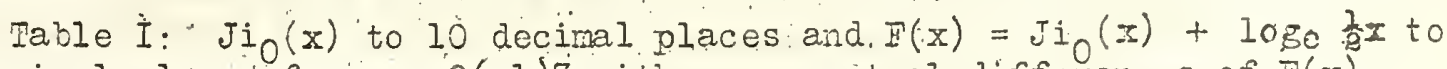
12 decimal pleces for $z=0(.1) 3$ mith even central differences of $I(x)$.

Table II: Jio $(x)$ to 10 decimal places, for $x=3(.1) 10(1) 22$ with even central differences up to $x=100$.

Table III: "Reduced" derivatives of $F(x)$ for $x=10(I) 2 I$ and $n=O(1) 13$, to 12 decimal places.

Reprinted from Journal of liathematics and Physics, Juno 1943.

7 pages, with cover, 25 cents. 
1.T22. Table of Coefficients in Wrumerical Integration Formulae...A. It. Loran The values of $B_{n}^{(n)}(I) / n$ ! and $B_{n}^{(n)} / n$ ! where $B_{n}^{(n)}(I)$ denotes the $n^{\text {th }}$ Sernoulli polynomial of the $n_{\text {th }}^{\text {th }}$ order for $x=1$ and $B_{n}$ denotes the $n^{\text {th }}$ Bernouli number of the $n^{\text {th }}$ order, were computed for $n=1,2$, ... 20. The quantities $B_{n}^{(n)}(1) / n$ ! are required in the Iaplace formula of numerical integration employing fprward differences, as well as in the Gregory formula. The quantities $B_{n}^{(n)} / \mathrm{n}$ ! are used in the Laplace formula cmploying backward differences.

Reprinted from Joumal of lathematics and Physics, June 1943. 2 pages; With cover, 25 cents.

1T23. Table of Fourier Coefficients........... I. Loman and J.. Lademan.

Whenever $\varphi(x)$ is a knorn polynomial whose degree does not exceed 10, the present table of the functions

$S(k, n)=\int_{0}^{1} x^{k} \sin n \pi x d x$ and $c(k, n)=\int_{0}^{1} x \cos n \pi x d x$ to $10 D(1<k<10, i<n<100)$, will facilitate the evaluation of the first hundred Fourier Coefficients:

Reprinted from Journal of lathematics and Physics, Septeraber 1943. 11 pares, with cover, 25 cents.

12T24. Coefficients for Numerical Differentiation with Central Differences... ... Eerbert E. Salzer.

Coefficients are given for derivatives as far as the 52nd. For the first 30 derivatives, exact values are given for coefficients of the first 30 differences, and also exact values are given for some coefficients of differences beyond the. 30 th. For the other coefficients, values are given to 18 significant figures.

Reprinted from Journal of lathematics and Physics, Septenber 1943. 21 pases, with cover, 25 cents.

1iir25. Seven-Point Lagrangian Integration Iormulas, ...G. Blanch and I. Rhodes. Fornulas (not requiring differences) are given for the intecral $f(x)$, when the latter has been approximated by polynomials of degree six, thus affording greater accuracy than by Simpson's rule; or for comparable accuracy, permitting the evaluation of integrand at fewer points in the region. Certain remainder terms are also considered.

Reprinted from Journal of Watheratics and Physics, December 1943. 4 pases, with cover, 25 cents:

1.I26. A Sliort Table of the Pirst Five Zeros of the Transcendental Equation $J_{0}(x) Y_{0}(k x)-J_{0}(k x) Y_{0}(x)=0, \ldots \ldots . A$. J. Iowan and $\dot{A}$. Hillman.

The first five zeros of the above equation prere computed for $z=11 / 2,2,21 / 2,3,31 / 2,4$. Zeros are given in Table I. The products of these zeros by $(\mathbf{k}-\mathbf{I})$ are given in Table II.

Reprinted from Journal of liathenatics and Fhysics, December 1943. 2 pages, with cover, 25 cents. 
it27. Table of Coeficients for Inverse Intérnolation with Central Difference .......Eerbert E. Salzer.

Contains tables giving the live fourth order coefficients for $m=0(.001) 1.000$; to 10 decinals (good to about a unit in the last decine and also the ten sixth order coefficients for m $=0(.1) 1.0$; exact values. A. condonsed one-page table of fourth order coefficients.j.t intervals of 0.1 is.also "fiven for convenience in case's where a larger table is unecessary.

Reprinted from Journal of Lathematics and Physics, Decenber 1943. 10 pages, with cover, 25 cents.

IT28. Table of $f_{n}(x)=\frac{n !}{\because(x / 2)^{n}} J_{n}(x) \ldots$ The Lathenatical Tables Project.

Values are given for $z \leqslant 10$, and $n \leqslant 20$, in the folloring range: $f_{2}$ and $f_{3}, \quad 0(.01) 10 ; 9 D ; \quad f_{4}$ and $f_{5}, 0(.01) 5.50,6.5(.1) 10 ; 9 D$ $f_{6}$ to $f_{8}, 0(.01) 1.50,1.5(.1) 10 ; .3 D ; \quad f_{9}$ to $f_{20}, 0(.1) 10 ; 9 D$. eirtries:

Modified second contral differences are tabulated aloisside the

Reorinted from Jourrnal of ifathenatics and Physics, February 1944. 16 pases, with cover, 25 cents.

1T29. Table of Coefficients for Inverse Interpolation With Advancing Differences....... jerbert E. Salzer.

This table may be regarded as a comanion table to lmat, "Table of Coefficients for Inverse Intelpolation with Central Differences." It coitains tables giving values to 10 decimal places for

$$
\begin{aligned}
& 4 \text { th and } 5 \text { th order terris for } i n=0(.001) 1.000 \text {; } \\
& 6 \text { th order terms :.. for } n=0(.01) 1.00 \text {; and. } \\
& 7 \text { th and } 8 \text { th order teris for } n=0(.1) 1.0 \text {. }
\end{aligned}
$$

All. these values are correct to about half a unit in the tenth deciral place with the exception of the coefficient of

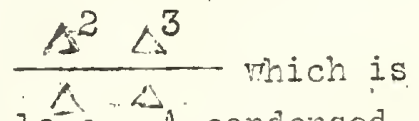
accurate to pithin a unit in the tenth decimal place. A condensed one-page table of coefficients of the fourth, fifth and sixth order torr at intervals of 0.1 , is also given for the sale of convenionce.

coefficients of the second and thitd order terms $\frac{m(1-m)}{2}$ and $\frac{m(1-m)(m-2)}{6}$ respactively, vare not tabulated since they are both tabulated at intervals of 0.0001 by the "lathesatical Tables Project in $t^{*}$ "Tables of. Iagrangian. Interpolation. Coefficionts" published by the Colur University Press, Mew Yorix City. For:m (there "p") ranging from" 0 to l, $\frac{m(I-m)}{2}$ is given by $-A_{-I}$ in the threc-point table and $\frac{m(I-m)(m-2)}{6}$ is given by $A_{-1}$ in the four-point table.

Reprinted from Journal of Iathematics and Physics, Niay 1944. 28 pages, with cover, 25 cents. 
M30.. A New Formula for Inverse Interpolation................ Salzer.

This paper is devoted to the derivation of a formula for inverse interpolation in a table of equally spaced arguments. The resulting formula is more concise and convenient than those in existence. It involves neither differences nor polynonial coefficients other than small porers. In use it vill be found much simpler and quicker than tho se given by Davis, Aitken, Steffensen and luilne-Thomson. In a sense, it is the analogue of the Iagrangian formula for direct interpolation without differences (that is, in tems of the tabular entries only) if the usual expression is rearranged in terms of powers of the argument $p$.

Reprinted from Bulletin of the American Wathematical Society, August 1944. 4 pages, with cover, 25 cents.

Iin31. Coefficients for Interpolation Within a Square Grid in the Comolex Plane....A. N. Iorran and E. E. Salzer.

The accompinying table gives the exact values of the real and imaginary parts of the 3-point and 4-point coefficients for both $p$ and $q$ ranging from 0 , to $l$ at intervals of 0.1 .

The present table is particularly useful when interpolation is to be carried out either for an isolated argunent or for a largo number of arguments which are irregularly scattered. Thus for a 4 -point interpolation for a single argurient, the process of interpolation based on the present table requires a total of 4 complex multiplications (equivalent af 16 ardinary multiplications) and 2 additions whereas the method of interpolation in the real and iraginary parts each considered as a function of $x$ and $y$, using real 4-point Iagrangian interpolation coefficients requires 40 multiplications and 10 additions. The table is homever not an efficient tool for carrying out an extensive and systematic process of subtabulation. For such task the latter method involving the use of real interpolation coefficicnts' is almost trice as efficlent from the standpoint of the tatal nuaber of multiplications and additions.

Reprinted from. Joumal of liathematics and Physics, August 1944. 11 pages, with cover, 25 conts.

10132. Table of Coefficients for Differences in Terms of the Derivatives. .......Eerbert E. Salzer.

The table list's the exact values of the coefficients $B_{m, s}$ for $m=1,2, \ldots 20$ and $s=m, 13+1, \ldots 20$, for calculating the $m^{\text {th }}$ advancing difference by means of hiarkoff:'s formula. It till be useful, to any one who wishes to construct difference tables for functions whose derivatives are lnomn:

: Reprinted from Journal of liathematics atid Physics, Noveraber 1944. 4 páges, with cover, 25 cents. 


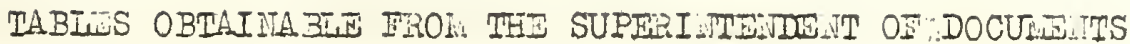

Orders for either of these two tables should be sent to the superintendent of Docusients, Government Printing uffice, Washington, D. C., accompanied by renittance drawn to his order:

Coordinate Conversion Tables. Published as Technica.1 lianual "Tiw $4-238$ of the

Table I:

Tar Department.

$A$ sin $x$ and $A \cos x$ trhere $x$ is in mils,

$$
\text { A, }[O(1) 100 ; \text { SD } 7 \text {; I, ГO(1)8007. }
$$

The mil is $1 / 1600$ of a right angle. The unit in which $A$ is expressed vill determine the unit of the entry--if $A$ is in yards, the entries.in this table are to be taken as yards.

Since these values represent products of $\sin x$ and $\cos x$ by $A$, values of the functions for any value of $A$ correct to 5 and soratires 6 significant figures may be obtained from the table by simple addition.

Table II:

Sin $x$ and $\cos x, r(1) 800 ; 8 D^{7}$.

This table may be used thenever higher accuracy than that afforded by the Table $I$ is desired.

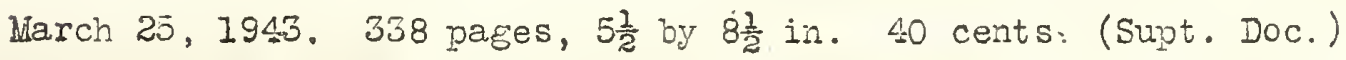

Fydraulic Tables (2d ed.) Published by the Corps of Engineers, War Department.

These tables were prevared and published primarily for the use of the various offices of, the Corps of Engineers, U. S. Army, in comection With the design of flood protection woriss. The range of many existing tables had been found inadequate for the large rivers, great depths, and steep slopes encountered in flood control pork. It ras also found desirable to compute several nom tables. The new tables will be especially useful in solving the lianing formula in its various forms

This handbool contains 46 hydraulic tables especially applicable to the solutions of problens of open channel flom. It is dividod into three sections; Section I consists of an extension of Tables 106, 121, and 133 in "Fandbook of Hydraulics" (1939) by Eorace 7 . King; Section II is an extension of Tables $14-18$ and 47 in "Hydraulic and Excavation Tables," 8th edition, 1940, by the Bureau of Reclanation; Section III, Wiscellaneous New Tables, i. e., (a) fractional powers of numbers, (b) normal depth in channels of infinite width, and (c) Waning formula tables giving the velocity of water for variars coefficients of roughness.

(1944) viii + 565 pages. Blue initation leather flexible cover, $4 \frac{1}{2}$ by $6 \frac{3}{4}$ in. $\$ 1.00$. (Supt. Doc.) 


\section{TABLES OBTAIHABLE FRO: THE COIULABA UNIVIRSITY PRESS}

The following four tables can be obtained frorn the Columbia University Press Morningside Heights, Netr York 27, iv. Y.

Table of the Reciprocals of the Integers from 100,000 through 200,009.

Tables of reciprocals are in frequent use by spectroscopists for the conversion of wave lengths into wave numbers, and vice versa. They may be applied also to all manner of computations, especially with calculating machines, by using multiplication to perform an indicated division. To carry out these operations the computer may make use of the 7-figure reciprocals of Oakes or Cotsworth. However, in the interval from 100,000 to 200,000 the differences between the successive entries of these tables vary from 1000 to 250 and interpolation betreen the tabular entries is soine that difficult. To facilitate the use of reciprocal numbers, it was therefore decidod to expand by tenfold the scope of the existing tables in this interval.

Preparation of manuscript tables was begun in December, 1934, by $\mathrm{Dr}$. C. C. Kiess of the National Bureau of Standards. As a result of nunerous requests for the roproduction of the table, the manuscript was given to the liathematical Tables Project in liarch 1940. This project recomputed the values, checked them against the iJational Bureau of Standards iss, and prepared the table for publication.

(1943) viii + 201 pages. Buckram cover. \$4.00 (Col.Univ.Press).

Table of the Bessel Functions $J_{0}(z)$ and $J_{I}(z)$ for Complex Arguments.

Bessel functions of orders zero and one are encountered in the general solution of boundary value problens arising in the theory of potential, heat conduction, and wave motion, when the domin is bounded by a circle or $a$. circular cylinder. In particular, they occur in the problem of propagation of electromagnetic waves with a straight wire as a guide (in an isotropic medium), the theory of the skin effect for poorly conducting wires, the problern of oscillatory motion of a sphere in a viscous medium, the vibration of a heavy chain in a resisting medium, and in many other boundary value problerss.

In spite of their great importance in theory and application, Bessel functions have scarcely been tabulated for complex argurnents. Aside from tables for purely imaginary arguments and for arguments in the form $r \sqrt{i}$, Hayashi's short tables of $J_{0}(z)$ and $J_{l}(z)$ are the only ones in existence. To reet the need for more adequate tables, these functions are tabulated in the present volurne for argument-points defined in polar coordinates. Along each of the rays $\varphi=0^{\circ}, 5^{\circ}, \ldots 90^{\circ}$, ten-place values of the real and imaginary parts of $J_{0}(z)$ and $J_{1}(z)$ are given for moduli ranging from 0 to 10 at intervals of 8.01 .

(1943) xliv + 403 pages. Euckran cover. $\$ 5.00$ (Col.Univ.Press). 
Table of Circular and Hyperbolic Tangents and Cotangents for Radian Arguments.

The min table in this voluine is devoted to the circular and hyperbolic tangents and cotangents, for radian argunents ranging frow. 0 to 2 at intervals of 0.0001 . Supplementary tables for all. four functions over the range iron 0 to 10 at intervals of 0.1 are also included. These tailes may be regarded as forming a conpanion volune to the "Tables of circular. ainc Hyperbolic Sines and Cosines "Which appeared in 1939 (See ins on page 2 of this list). The entries in the latter volurie are given to nine decinal places--equivalent to eight, nine, or ten significant figures als suost everymere. Since the tangent and cotangent vary from - xjto xover a range of $\pi$, the tables $i$ in this volume are given to eight significant figures rather thain to a fixed number of decinal places. An excention has been wade in some entries near the origin and near $\frac{1}{2} h^{\prime}$, where a fer additioni significant figures are given for the sake of regularlity in format.

(1943) zxuviii + 410 pages. Buccroin cover." \$5.00 (Col.Jniv.Press).

Table of Iasrangian Intermolation Coefficients.

Several täles are available siving the coefficients recuired in interolation with the aid of differences. "Horrever, there are no extensive tajles for interpolating by means of the most fundanental we thod--the Lastangian formua-mhich inyolves only the tabular entries theirselves and reguires no differences. The Jagrangian interpolation forma ( Ti thout the remainder term) aproxinatés a given function by a polrnomial. The polrnomial of degree $n-\underline{l}$, determined by as an n-point interpolation polynomial. The present. volune extends the ferm existing tables of La grangian intemolation coefficients in these n-noint polynonials for $n=3,4, \ldots, 11$ by giving the entries at smaller intervals of tho argurent and by masing adequate provisions for interpolation near the beginuing and near the end of a table.

-uthermore, all the coericients of Everett's central difenence formula involving diferences up to the eighth order are inentical tith certain Jagrangian coeficients given in this table. In particular, Everett's second-order coefificients are here tabulated at the interral of 0.0001 - a suller interval than in other existing tables, Coefficients of the Gregory-iverton and newton-Gaus formulas may also be found in this volune.

(1044) xxrvi + 392 pages. Bucrran cover. \$5.00 (Col.Univ.Press). 
TA BLES AVAIIABLE ILSIIVEEFE

The ten tables listed below can be consulted in livraries maintaining a file of mathenatical and technical journals" "No reprints of them"are obtainable from the Bureau.

On the Computation of Second Differences of the Si(x), Ei(x), and Ci(x) Functions Bulletin of the American iathenatical Society (531 W. 116th St. , Wer! York 2 ? Y.), 45, No. 8, 583-588 (August. 1939). By Arnold it. Loran.

On the Distribution of Errors in the nth Tabular Differences. Arnold iN. Iowan and Jack Iaderman. Annals of iathenatical Statistics (Institute of

Wathematical.Statistics, E.-S. Jlds, Secretary, Carnegie Inst. of Technology. Pittsburgh; Pa.), ㅈ. No. 4, 360-364 (December 1939).

Note on the Computation of the Differences of the Si(x), Ci(x), Ei( $x)$, and - Ei( Functions. Milton Abramowitz. Bulletin of the American Mathematical Society, 46, iNo. 4, 332-333 (April 1940).

Errors in Fayashi's Table of Bessel Functions for Complez Arguments. Arnoldiv. Iowan and Gertmde Blanch. Bulletin of the American latheratical Society, 47; iNo. 4, 291-293 (April 1941):

Tables of Steliar Functions for "Point-Source" Lodels. G. Blanch, A. iN. Iowan, F. Tarshale, and I. A. Bethe. Published under the title: "The Internal Temperature-Density Distribution of the Sun" in the Astrophysical Journal, (Yerlces ubservatory, Williams Bay, Wisconsin'), 94, 37-45 (July"1941).

On the Inversion of the a-Series Associated \#ith Jacobian Elliptic Munctions.

A. I. Iowan, G. Blanch, and Horenstein. Bulletin of the Arrerican iathena tical Society, 48 , ITo. 10, 737-738 (Uctober 1942).

A Table of Coefficients for Numerical Differentiation. Amold I?. Lowan, Herbert I. Salzer and Abraham Eillman. Bulletin of the American Wathematical Society, 48 , No. 12, 920-924 (December 1942).

Loots ô $\operatorname{Sin} z=z$. A. P. Hillman and H. E. Salzer. (Gives the first ten non-zero roots of sin $z=z$ in the first quadrant to siz decimal places. Roots of sin $z=z$ There $z=z+i y$.) Philosophical inagazine (Taylor \& Francis', Itd., Red Iion Court, Fleet Street, London, I.C.4i, Fing: Iand). Ser. 7, xxxiv, 575 (August 1943).

Coefficients for Numerical. Integration with Central Differences. Ferbert E. Salzer. Philsophical liagazine, Ser. 7, xurv, 262-264 (April 1944).

Formulas for Complez Interpolation. Armold il. Jowan and E. D. Salzer. quarterly of Applied iathematics (Brom University, Providence, R.I.), II, IJo. 3, 272-274 (October 1944). 